\title{
La fenomenología del resentimiento según Scheler y Girard a la luz de la acedia en la Suma de Teología de Tomás de Aquino
} (Phenomenology of resentment according to Scheler and Girard in light of sloth in Thomas Aquinas' Summa Theologiae)

\section{MIGUEL ÁNGEL BELMONTE}

Universitat Abat Oliba CEU, CEU Universities, Barcelona, España belmonte@uao.es

ORCID: 0000-0002-8653-7735

\begin{abstract}
Después de que Friedrich Nietzsche expusiera el fenómeno del resentimiento mediante un supuesto desenmascaramiento de un complejo emotivo oculto, autores posteriores, como Max Scheler y René Girard, matizaron el análisis nietzscheano aplicándolo a diversos ámbitos antropológicos y sociales. Muchas de las principales aportaciones de estos análisis contemporáneos encuentran sus precedentes en autores anteriores, modernos y medievales. Seis siglos y medio antes de Scheler, Tomás de Aquino ofrece en dos cuestiones de su Summa Theologiae dedicadas a la acedia y la envidia una serie de precisiones conceptuales y observaciones psicológicas que coinciden en gran parte de su fondo y, en ocasiones, en la forma, con ciertas caracterizaciones del resentimiento. Demostramos, apoyándonos en numerosas referencias textuales, los paralelismos entre la fenomenología scheleriana del resentimiento y la exposición tomasiana de los vicios capitales.
\end{abstract}


Abstract. After Friedrich Nietzsche explained the phenomenon of resentment through a supposed unmasking of a hidden emotional complex, later writers, like Max Scheler and René Girard, qualified Nietzschean analysis by applying it to various areas of anthropology and society. Many of the main contributions from these contemporary analyses find their roots in earlier authors, both modern and medieval. Six and a half centuries before Scheler, Thomas Aquinas offered in two questions of his Summa Theologiae dedicated to sloth and envy, a series of conceptual clarifications and psychological observations, which, in large part, share the same content and, at times, the form, with certain characterisations of resentment. Using many text references, we show the parallels between Schelerian phenomenology of resentment and the Thomasian explanation of the deadly sins.

Keywords: vicios capitales; falsedad moral; Nietzsche; Scheler; Girard; Tomás de Aquino.

Keywords: deadly sins; moral falsehood; Nietzsche; Scheler; Girard; Thomas Aquinas.

\section{Introducción}

En el primer tratado de La genealogía de la moral, Nietzsche desarrolla su crítica más elaborada y sistemática de una serie de conceptos morales. En ella destaca especialmente el de resentimiento, elemento decisivo en el conjunto de la explicación nietzscheana acerca de la transvaloración que conduce desde la moral de los señores hacia la moral de los esclavos. Toda la tradición judeocristiana y la civilización occidental entera son reinterpretadas desde una nueva óptica: las virtudes cristianas y sus derivadas son denunciadas como complejas mentiras y autoengaños. El desenmascaramiento que Nietzsche pretende haber realizado se apoya en el análisis de un complejo emotivo oculto que supuestamente habría llevado a transformar el deseo natural de venganza contra el enemigo en un amor tan explícito como, en el fondo, falso, hacia él y en una postergación de la venganza terrena en forma de una condena eterna de los malvados (Nietzsche 1971, 40). Nietzsche aduce citas de Tertuliano, Dante e incluso Santo Tomás de Aquino para mostrar el carácter nuclear de ese conjunto de emociones y juicios consiguientes que bautiza con el término francés ressentiment, a falta probablemente de un término más apropiado en su propia lengua (Nietzsche 1971, 56) La traducción de Sánchez Pascual al español vierte el término sin mayores problemas como 'resentimiento'. De modo parecido en 
otras traducciones a las lenguas románicas. Algunos especialistas rechazan esta operación para otras lenguas: "Nietzsche's notion of ressentiment also incorporates revenge and is sometimes referred to directly as 'the spirit of revenge'. It is a technical term for him, left in French in the original, so the common translation of ressentiment as resentment is inappropriate." (La Caze 2001, 38). Ciertamente, Nietzsche podría haber utilizado el término alemán Schadenfreude que literalmente combina la idea de alegría y dolor, con connotaciones cercanas a la malicia y la envidia (Perrine and Timpe 2014, 236). En cualquier caso, Nietszche encontró más adecuado usar el término francés y Max Scheler justificó, en las observaciones preliminares de su ensayo sobre esta cuestión, la continuación de ese uso. Para Scheler es fundamental, por un lado, la presencia del prefijo re que indica reacción o repetición de un modo explícito. Por otro, el término ressentiment ofrece la nota de emoción negativa y hostilidad, aspectos también nucleares en el concepto (Scheler 1998, 16-17).

\section{Desarrollo contemporáneo del concepto de resentimiento: Nietzsche, Scheler, Girard}

Más allá de estas dificultades terminológicas, Scheler se enfrenta a un Nietzsche que, a pesar de utilizar aparentemente un estilo más discursivo en la Genealogía de la moral -en comparación con el estilo aforístico predominante en el resto de sus obras principales- no abre la puerta a diálogo filosófico alguno. Al fin y al cabo, el objetivo reconocido por Nietzsche una y otra vez no es un avance en el conocimiento especulativo: “iqué me importan a mí las refutaciones!” (Nietzsche 1971, 21) sino dar un paso más en su propio proyecto.

Sin embargo, Max Scheler sí que intenta someter a análisis las ideas contenidas en la Genealogía de la moral, muy especialmente las que se desarrollan en el primero de sus tres tratados, centrando su análisis en el concepto de resentimiento, en su valioso ensayo Das Ressentiment in der Aufbau der Moralen, traducido por Gaos como El resentimiento en la moral, aunque más literalmente sería algo así como el resentimiento en 
la construcción de la moral. Y es que Scheler no niega la influencia real del fenómeno del resentimiento en la construcción de la moral moderna, especialmente en sus versiones más filantrópicas y cosmopolitas. Lo que refuta es su supuesta función en la configuración de la caridad cristiana que, para Scheler, está en las antípodas de la filantropía moderna. La defensa es notable y sólida, aunque lo que resulta más interesante en dicho ensayo es el capítulo dedicado a la fenomenología del resentimiento.

Scheler describe el resentimiento como una autointoxicación psíquica causada por una impotencia continuada que se traduce en una negación de la realidad. Tal negación se da en forma de transformación del juicio acerca de la realidad misma. Se trata de un sentimiento de carácter, en el fondo, reactivo aunque bajo cierta apariencia de espontaneidad. Resulta espontáneo, por ejemplo, reaccionar inmediatamente a un ataque físico o verbal. Pero, si la reacción inmediata resulta inviable, puede surgir en el ofendido el deseo de venganza. Este deseo no implica por sí solo resentimiento. Pero es ya como un precedente del resentimiento por lo que tiene de aplazamiento forzado por una debilidad previa, se posterga la acción y se disuelve la espontaneidad, aunque se mantiene el carácter reactivo. La venganza se hace incompatible con el resentimiento en lo que tiene de consumación:

El resentimiento es una autointoxicación psíquica con causas y consecuencias bien definidas. Es una actitud psíquica permanente, que surge al reprimir sistemáticamente la descarga de ciertas emociones y afectos, los cuales son en sí normales y pertenecen al fondo de la naturaleza humana; tiene por consecuencia ciertas propensiones permanentes a determinadas clases de engaños y juicios de valor correspondientes [...] El punto de partida más importante en la formación del resentimiento es el impulso de venganza [...] La venganza en sí es una vivencia que se basa en otra vivencia de impotencia; siempre, por tanto, cosa del ‘débil' en algún punto. (Scheler 1998, 20-21)

La imposibilidad de consumación de la venganza se traduce a menudo en sentimientos de envidia, ojeriza o, incluso, perfidia. Esta última consiste en un impulso hondo e íntimo que se delata en gestos impensados: el pérfido, por ejemplo, no puede frenar la exteriorización de su alegría al conocer el 
mal ajeno. En la ojeriza, se hace un esfuerzo mental específico para asociar ciertos objetos o valores a unas personas determinadas a las que se tiene envidia, como un medio para destruir su prestigio y, así, indirectamente, provocar el aumento del propio ego. Algo parecido ocurre en cierto tipo de crítica dirigida hacia quienes ocupan cargos de responsabilidad y pronunciada por quienes, en el fondo, no hacen más que rehuir cualquier tipo de responsabilidad y serían incapaces de gobernar. Se trata en este caso ya de una crítica resentida por la inactividad asociada y por no querer realmente extirpar el mal denunciado sino necesitarlo para desahogarse y ocultar las propias limitaciones (Scheler 1998, 27).

La envidia a menudo va mucho más allá de un sentimiento más o menos inofensivo, como sugiere el uso frecuente en español de la expresión 'sana envidia'. Así, por ejemplo, desde el momento en que la envidia, por efecto de la intensificación de los celos, la competencia y la rivalidad con el sujeto envidiado, adquiere el rango de envidia 'existencial'. En tal caso ya no se limita el sujeto a desear vivamente el objeto que posee otra persona, sino que se ve en la existencia misma de la otra persona la causa de todo el malestar propio. Ya no es simplemente que al poseer el otro lo que yo quiero, él me impida tenerlo. Se trata de que en realidad el otro es quien yo querría ser. Entonces no solo se ve al otro como la principal razón de mi infelicidad, sino que la situación carece completamente de solución practicable. Esta confusión entre las personalidades de los dos rivales, precedida de un proceso delirante de envidia creciente, ha sido también ampliamente estudiada por el padre de la teoría del deseo mimético, René Girard, quien cita profusamente a Scheler al comienzo de su obra Mentira romántica y verdad novelesca. Girard considera que todos los ejemplos que pone Scheler de resentimiento son también ejemplos de lo que él denomina mediación interna:

La palabra resentimiento subraya [...] el carácter de reacción, de réplica, que caracteriza la experiencia del sujeto en este tipo de mediación [interna]. La admiración apasionada y la voluntad de emulación chocan con el obstáculo aparentemente injusto que el modelo opone a su discípulo y recaen sobre este último bajo forma de odio impotente, provocando así la especie de autointoxicación psicológica que tan bien ha descrito Max Scheler. (Girard 1985, 17) 
En la mediación interna girardiana, la comparación con el otro, siendo el otro alguien sentido como no muy diferente ni distante, es requerida para la formación de nuestros propios deseos. El problema parece surgir cuando la imitación del deseo ajeno conduce al enfrentamiento por la posesión de un mismo objeto indivisible. Esto es más posible precisamente cuanto más cerca estén, o se perciban, los dos sujetos rivales: "No sospechamos, por ejemplo, que los celos y la envidia, al igual que el odio, no son más que los nombres tradicionales dados a la mediación interna, nombres que casi siempre, nos ocultan su auténtica naturaleza." (Girard 1985, 17-18) El autor francés destaca cómo en Scheler, igual que en Nietzsche, la clave del resentimiento está en la facilidad de la inteligencia para formarse un juicio que trastorna la realidad. Es la imaginación descontrolada del sujeto envidioso la que le hace ver complots, persecuciones y tramas, donde no hay más que unas relaciones de posesión reales previas a las que no se quiere reconocer como tales: "[Scheler] observa, por otra parte, que no existiría envidia, en el sentido literal del término, si la imaginación del envidioso no convirtiera en una oposición concertada el obstáculo pasivo que el poseedor del objeto le opone, debido precisamente a su posesión.” (Girard 1985, 18-19) El problema del envidioso es que su propia envidia le impide reconocer que el origen de su malestar no está en la ausencia del objeto deseado, sino que está en el mediador interno: "todo se aclara y se organiza en una estructura coherente si renunciamos, para explicar la envidia, a partir del objeto de la rivalidad y si convertimos al propio rival, es decir al mediador, en el punto de partida del análisis y en su punto de llegada.” (Girard 1985, 19) Por eso en el envidioso resentido es más fuerte el odio hacia el mediador interno que el amor por el objeto del que carece: "Sólo el ser que nos impide satisfacer un deseo que él mismo nos ha sugerido es realmente objeto de odio. El que odia se odia en primer lugar a sí mismo, a causa de la admiración secreta que su odio oculta." (Girard 1985, 17) Un ejemplo de esta envidia que acaba generando odio hacia el mediador y, de rebote, odio hacia uno mismo, lo tenemos en el protagonista de El rojo y el negro Julien Sorel. De extracción humilde, no soporta carecer de la nobleza de sangre de sus rivales, lo que le impide ser visto por la aristócrata Mathilde como un igual: “¡Santo cielo! 
¿Por qué yo soy yo?” (Stendhal 2014, 462) llega a preguntarse Sorel. Girard muestra a través de la obra de Stendhal numerosos ejemplos de la mediación interna. El juego de los celos, las envidias, la competencia, etc., aparecen una y otra vez. También Scheler propone como tipo de resentido el alma romántica de la que Sorel es sin duda un caso especial:

está siempre el alma romántica influida por el resentimiento, hasta cierto grado por lo menos, cuando su nostalgia de alguna región del pasado histórico (Hélade, Edad Media, etc.) no descansa primordialmente en la especial atracción que los peculiares valores y bienes de esta época ejercen sobre el sujeto, sino en un interior movimiento de desvío en la época propia, cuando toda alabanza y ponderación del 'pasado' van unidas a la intención concomitante de desvalorar el presente y la realidad que circunda al sujeto. (Scheler 1998, 44-45)

Precisamente tal es el caso de Julien Sorel, que constantemente idolatra a Napoleón y su época mientras que desprecia la propia. En este sentido, es de destacar que Stendhal subtitula su novela 'Crónica del siglo XIX. Crónica de 1830'.

Tanto en los ejemplos extraídos de la literatura por Girard como en los tipos vitales de envidiosos resentidos propuestos por Scheler, el resentimiento viene ligado a una actitud especial en la que el sujeto inconscientemente resentido comienza por escoger un modelo, algo así como un héroe, con el cual establece de modo enfermizo una comparación valorativa obsesiva. Para Scheler, lo enfermizo no radica en la elección de un modelo. Cualquier persona corriente y sana tiene sus modelos vitales. Presumir de no tener modelo sería más propio de una actitud snob que de una actitud noble. Lo enfermizo aparece cuando el sentimiento predominante es el de la ansiedad por salir vencedor en cualquier comparación. Esta ansiedad es la que lleva a una tergiversación de la realidad. Se convierte al modelo en rival, en enemigo, y hasta en causa de nuestra infelicidad. Y cuando se descubre uno a sí mismo incapaz de salir vencedor en la comparación, se llega incluso a aborrecerse a sí mismo. Esto es algo que tanto Scheler como Girard supieron percibir claramente en ciertos tipos del hombre contemporáneo, especialmente en el romántico, pero no reducido a una corriente o época 
histórica sino a una actitud enormemente habitual y extendida en el mundo occidental actual.

\section{El resentimiento: una mirada hacia el pasado}

Antes de conectar la fenomenología scheleriana del resentimiento con el pensamiento de santo Tomás de Aquino, cabe destacar la aportación que se halla en el teólogo inglés de la primera mitad del siglo XVIII Joseph Butler. Concretamente, destacamos dos sermones dedicados al resentimiento y el perdón de las injurias. Allí distingue entre el resentimiento asociado a una ira repentina y el asociado a una ira mantenida. El primero es un medio necesario para la supervivencia mientras que el segundo es el que hay que vigilar para que no degenere en rencor o en malicia. Uno de los síntomas de que nos estamos dejando llevar por un resentimiento vicioso es que aumente nuestra ira al sentir la injuria como propia. De este modo Butler relaciona el resentimiento moralmente peligroso con los sentimientos de autoestima heridos. Por eso, en la última parte de estos sermones advierte contra el peligro de que el resentido distorsione la realidad, empezando por valorarse a sí mismo por encima de lo que uno realmente es. La solución está en el reconocimiento humilde de la propia verdad existencial. En pocas palabras condensa Butler la solución contra el resentimiento: se trata de arraigarse en la verdad, en la realidad de las cosas: "Observe, we only ask men to look at things as they are" (Butler 1896, 136) Uno de los tipos de resentimiento a los que se refiere Butler es positivo moralmente y consiste en algo virtuoso especialmente desde el punto de vista social -algo parecido a la indignación hesseliana-y da pie a una mayor capacidad para perdonar la afrenta personal pero, a la vez, una mayor inclinación a denunciar la injusticia contra la comunidad. Por el contrario, el resentimiento scheleriano, aunque incluye la nota esencial de la inexistencia de la acción física de venganza, es del todo incompatible con el verdadero perdón (La Caze 2001, 40).

Es oportuno señalar la cercanía de esta orientación moral de Butler con la afirmación, dos siglos antes, de santa Teresa de Ávila "la humildad es andar en la verdad” y la recomendación frecuente de no concluir la oración sin 
un momento para el conocimiento de sí mismo que nos evite engreírnos: "Una vez estaba yo considerando por qué razón era Nuestro Señor tan amigo de esta virtud de la humildad, y púsoseme delante, a mi parecer sin considerarlo, sino de presto, esto: que es porque Dios es suma Verdad, y la humildad es andar en verdad; que lo es muy grande no tener cosa buena de nosotros, sino la miseria y ser nada, y quien esto no entiende, anda en mentira.” (Teresa de Jesús 1984, 390)

También el pensador alemán Josef Pieper en su análisis de las virtudes hace hincapié en el carácter correctivo y sanador, no sólo desde una perspectiva moral sino incluso médico-psicológica, del principio de reconocimiento de la realidad:

Un resultado de la psicología, o mejor dicho, psiquiatría moderna, que a mi parecer nunca ponderaremos demasiado, hace resaltar cómo un hombre al que las cosas no le parecen tal como son, sino que nunca se percata más que de sí mismo porque únicamente mira hacia sí, no solo ha perdido la posibilidad ser justo (y poseer todas las virtudes morales en general), sino también la salud del alma. Es más: toda una categoría de enfermedades del alma consiste esencialmente en esta 'falta de objetividad' egocéntrica. (Pieper 1980, 17-18)

Precisamente para Scheler cierto tipo de engaño estimativo resulta ser el elemento emblemático del resentimiento. Lo que empieza siendo una preocupación excesiva por salir ganando en la comparación con el rival, se transforma fácilmente en una negación de nuestra propia debilidad y, finalmente, en una negación del bien objetivo, de los valores morales y de la bondad esencial de cada virtud:

Esa conciencia de la superioridad o de la igualdad, que el hombre 'vulgar' busca para resolver la tensión, es alcanzada, o bien rebajando engañosamente las cualidades valiosas del objeto de la comparación, o bien 'cegándose' el que compara para esas cualidades; pero, en segunda línea -y en esto consiste la obra capital del resentimiento-, mediante la mistificación y falseamiento de los valores mismos, bajo cuya existencia y vigencia los posibles objetos de la comparación poseen un carácter positivo y altamente valioso. (Scheler 1998, 34) 
En continuidad con las advertencias de Pieper, se ha subrayado recientemente el concepto de redundantia y su rol en la comprensión tomasiana de la unidad entre afectividad sensitiva e intelectiva (Echavarría 2016, 68). En el apartado siguiente tratamos de iluminar las intuiciones de autores como Scheler y Girard con la enseñanza contenida en las cuestiones dedicadas por Tomás de Aquino a los vicios contra la caridad, especialmente la acedia, limitándonos a la Summa Theologiae y sin referirnos a otras partes del corpus tales como los comentarios bíblicos (Roszak and Vijgen, 2015).

\section{Del resentimiento a los vicios contra la caridad: acedia y envidia}

Hemos visto cómo el concepto de resentimiento, comenzando en Nietzsche y siguiendo con el desarrollo scheleriano, apunta a una cierta forma de degradación moral que incluye como notas específicas el carácter reactivo, el aplazamiento sin fin de la venganza física y la transformación del juicio acerca de la realidad, incluso de la realidad espiritual o axiológica. De ahí que el modo de evitar el resentimiento y sus efectos sea precisamente el del reconocimiento gozoso de la realidad, la acción física y la perseverancia en el propio estado. El reconocimiento gozoso de la realidad es inseparable del agradecimiento al Creador: "no hay que amar a Dios por su cielo y su tierra, sino al cielo y la tierra, porque son de Dios, porque el amor eterno brilla a través de ellos como expresión sensible..." (Scheler 1998, 72) La acción física tiene su prototipo en el soldado, al que Scheler considera "el menos (...) expuesto al peligro del resentimiento" (Scheler 1998, 42) Y la perseverancia en el propio estado contrasta con uno de los tipos de resentido, el apóstata: "el apóstata es un hombre cuya vida espiritual no radica en el contenido espiritual de su nueva fe y en la realización de los fines correspondientes a ella, sino que vive solamente en lucha contra la antigua y para su negación” (Scheler 1998, 43)

Veamos ahora en qué medida el tratamiento tomasiano de la acedia en la Suma de Teología permite ahondar en la comprensión del fenómeno del resentimiento. Hay una serie de paralelismos sorprendentes entre la fenomenología del resentimiento de Max Scheler y los ejemplos del Aquinate. 


\subsection{El rechazo del bien divino}

Tomás define la acedia como una tristeza indebida contraria al gozo que implica el bien divino y Scheler conecta el resentimiento directamente con la filantropía moderna en cuanto que ésta es manifestación de un odio reprimido contra Dios. La filantropía propia de cierta modernidad filosófica y política no consiste en la mera familiaridad que une a los seres humanos entre sí por la cual resulta agradable encontrarse unos con otros. Consiste más bien en un sentimiento artificial de amor voluntarista hacia la humanidad en su universalidad, como concepto. Tal humanidad es elevada a una categoría divina. Se exige un culto y unos mandamientos adecuados a esta nueva divinidad. Pero tales culto y mandamientos serán elaborados a partir de un sucedáneo de la religión tradicional. El Dios creador, redentor y providente no tiene cabida en el nuevo amor filantrópico a la humanidad. Scheler pone el acento en que la fuerza original de la filantropía universal moderna está en el odio a Dios y a todo lo que recuerde a Dios, su Iglesia y sus ministros (Scheler 1998, 99-100).

En la medida en que la filantropía universal moderna adora al ser humano en lo que tiene de ser natural y limitado en tanto que opuesto al Dios infinito, santo Tomás de Aquino no dudaría en catalogarla como un pecado mortal. Puesto que no se trata de un movimiento espontáneo descontrolado sino de algo más bien artificial, sistemático y elaborado desde la inteligencia, la filantropía moderna entraría claramente en el caso del horror y la repulsa al bien divino: “...el movimiento de la acedia se da a veces solamente en la sensualidad por la repugnancia de la carne hacia lo espiritual, y en este caso es pecado venial. Otras veces, por el contrario, llega hasta la razón, consintiendo en la huida, el horror y la repulsa del bien divino, prevaleciendo del todo la carne sobre el espíritu. En este caso es evidente que la acedia es pecado mortal” (Tomás de Aquino 1995, 320). En el fondo es la misma oposición entre el hombre y Dios que encontramos en la leyenda del Gran Inquisidor. En el célebre pasaje del genial escritor ruso Dostoyevski, en el que a menudo tanto Scheler como Girard se apoyan, el Gran Inquisidor exalta la capacidad del poder humano de organizar un mundo perfecto donde los poderosos den de comer a los pobres y les hagan 
felices sin necesidad de que intervenga Dios, incluso como alternativa exitosa al plan fallido de Dios. La profundidad de la obra de Dostoyevski la hace especialmente susceptible de ser interpretada como un antídoto contra el resentimiento o, todo lo contrario, si el propio resentimiento se convierte en criterio para juzgarla: “desde la óptica de las 'escuelas del resentimiento', la literatura nada tendría que decirle al hombre de las distintas épocas. Una lectura literaria exaltaría los ánimos de algún lector, en tanto que él supondría entender algo de la realidad, pero sería un iluso que yerra: sólo 'entiende' (mejor dicho, mal entiende) una ideología particular, la del escritor" (Quesada 2010, 227) Acertadamente se ha destacado que la falta de atención del pensamiento contemporáneo hacia la acedia se debe a que esta no se entiende sin entender aquello a lo que se opone, la caridad: "Aquinas is clear that acedia contradicts the joy of charity. It is a psychic obstacle which harms the supernatural life. That is why acedia is treated with such seriousness by the theologian, and that is why modern moralists with their limited this-wordly visión ignored it.” (Giertych 2019, 203)

\subsection{Rencor y resentimiento}

Al ser la acedia una tristeza ante el bien divino, el acídico fácilmente pasa de entristecerse ante la contemplación de otro que ha alcanzado visiblemente tal bien divino, a impugnar o rechazar al causante de su tristeza, que es ese mismo otro, ante el cual se indigna; de modo similar el resentido intentará evitar a toda costa la contemplación de sujetos agraciados con valores superiores, pero, cuando no tenga más remedio que observarlos, dirigirá su odio hacia la existencia misma del otro. Por eso, el resentido disfraza frecuentemente su envidia de indignación.

Santo Tomás distingue entre, por un lado, el indignado o nemesético, que puede serlo con toda justicia y amor ordenado al bien, y, por otro lado, el envidioso, figura del resentido, que se entristece de que los bienes sean alcanzados debidamente: "Por parte de aquel de cuyo bien siente tristeza el envidioso, la envidia se opone a la némesis. El nemesético, en efecto, se entristece de quienes obran indignamente [...] el envidioso, en cambio, se entristece del bien de quienes son dignos de él” (Tomás de Aquino 1995, 326). 
Esta tristeza viciosa llega a ser máximamente injusta cuando es efecto del aumento del bien divino en el prójimo: "hay un tipo de envidia considerado entre los pecados gravísimos, y es la envidia de la gracia del hermano, en el sentido de que alguno se duele incluso del aumento de la gracia de Dios, y no sólo del bien del prójimo" (Tomás de Aquino 1995, 327). Como explica el Aquinate, esta resistencia e incluso repugnancia ante el bien divino, puede conducir incluso al rechazo abierto de las personas que simplemente nos presentan dicho bien divino, sea porque ellos mismos son modelos de santidad, sea porque nos hablan de él como bien deseable y susceptible de ser alcanzado: "la impugnación de los bienes espirituales que contristan se hace, a veces, contra los hombres que los proponen, y eso da lugar al rencor" (Tomás de Aquino 1995, 322)

Precisamente el rencor constituye para Scheler un aspecto esencial del resentimiento: “El 'rencor' es, en efecto, ese enojo retenido, independiente de la actividad del yo, que cruza oscuro el alma y acaba formándose cuando los sentimientos de odio u otras emociones hostiles reviven repetidamente" (Scheler 1998, 17). Este rencor aparece claramente en ciertos movimientos sociales y políticos revolucionarios en los que lo decisivo no resulta ser el bien que se defiende sino el mal que se denuncia precisamente por ser presentado como bien por aquellos que lo sostienen:

esta conducta toma a veces la forma de un desvarío colectivo; así, por ejemplo, la inteligencia rusa [...] vierte con gusto su morbosa sed de sacrificio, su huida de sí misma, en 'fines' político-sociales y explica luego su morbosidad como 'heroísmo moral'. En general, ese tipo [...] con quien tropezamos modernamente cada día más [...] no es las más de las veces sino un pobre hombre vacío y movido por el egoísmo (Scheler 1998, 104)

Scheler señala el rechazo más o menos consciente del revolucionario clásico hacia las experiencias clasistas de su propia infancia. De esa manera, sugiere la importancia de los aspectos educativos en la génesis del resentimiento. Convenientemente se ha subrayado desde la óptica tomista la necesidad de una determinada experiencia (experimentum) en la educación de las pasiones (Martínez 2019, 243) en una dirección que podemos catalogar de 
preventiva respecto al riesgo de aparición de desviaciones resentidas. En definitiva, se trata de conectar, desde niños, la actitud contemplativa con la actitud gozosa. Tal es el mejor antídoto educativo contra el resentimiento: la experiencia elemental de la belleza (Gudaniec 2016, 85).

\subsection{El peligro de la ascesis}

Así como, según indica santo Tomás de Aquino, algunas circunstancias pueden empujar más que otras a la acedia sin que eso quite voluntariedad y carácter moralmente reprobable al acto en que se cede, también hay, según Scheler, algunos prototipos psicológicos de resentido en los que no forzosamente se cae en el resentimiento, pero sí que en ellos el peligro de caída es mayor.

El Aquinate, en continuidad con la tradición patrística, vincula la acedia con el demonio del mediodía y señala de qué manera ciertos elementos circunstanciales pueden favorecer la aparición de la acedia. Como la acedia es un tipo de tristeza, se puede favorecer su aparición en momentos de debilidad corporal. Por eso, para los que ayunan y se imponen mortificaciones, el momento de máxima debilidad corporal es especialmente susceptible de convertirse en el momento en que más aceche la acedia. Además, la conexión entre ayunos y sacrificios con el bien divino, al que se juzga como causa de aquellos sufrimientos, puede inclinar al desprecio de tal bien divino: "toda flaqueza corporal dispone de suyo para la tristeza, y por eso, quienes ayunan sufren sobre todo los ataques de la acedia hacia el mediodía, en que comienzan a sentir la falta de comida y se sienten agobiados por el calor del sol." (Tomás de Aquino 1995, 318-319)

También Scheler considera especialmente predispuesto al resentimiento a las personas que hacen profesión de ascetismo o de consagración como en el tipo del sacerdote. En este caso, el acento no está puesto tanto en la debilidad física sino, sobre todo, en la debilidad moral, en la renuncia del sacerdote a la acción física violenta frente a sus enemigos. Al estar obligado a manifestarse externamente como alguien pacífico y manso, el sacerdote corre el riesgo de desviar el odio a sus enemigos de modo sutil a través de luchas políticas partidistas, intrigas de sacristía, etc (Scheler 1998, 42). 
Solo cuando el sacerdote y el homo religiosus coinciden en el mismo sujeto se evita el peligro de caer en el resentimiento. En una línea parecida, los padres de la Iglesia reflexionaron a menudo sobre las tentaciones propias del estado religioso y se preocuparon de proporcionar desde una perspectiva teológico-moral las mejores vías para vencerlas. Así, por ejemplo, ya Evagrio Póntico en su exposición sobre la acedia, pone el acento en el aspecto curativo del reconocimiento gozoso de la realidad (Peretó Rivas 2011, 162-165).

\subsection{Igualdad y envidia}

Según santo Tomás, se envidia no a los que nos sobrepasan en mucho sino a los cercanos, a los cuales se juzga culpables de no haber alcanzado nosotros mismos la gloria que ellos sí alcanzan:

Dado que la envidia nos viene de la gloria de otro, porque aminora la que cada uno para sí desea, se sigue de ello que solamente se tenga envidia de aquellos con los que el hombre quiere o igualarse o aventajarles en su gloria. Esto no se plantea respecto de quienes están a mucha distancia de uno. Nadie, en efecto, si no es un demente, pretende igualarse ni aventajar en gloria a quienes son muy superiores a él; por ejemplo, el plebeyo respecto del rey ni el rey respecto del plebeyo, a quien tanto sobrepuja. De ahí que el hombre no tenga envidia de quienes están muy distantes de él por el lugar, el tiempo o la situación; la tiene, en cambio, de quienes se encuentran cerca y con quienes se esfuerza por igualarse o aventajar. Ciertamente, sobresalir ellos en gloria cede en perjuicio de nuestros intereses, y por eso se origina la tristeza. (Tomás de Aquino 1995, 323)

La penetración psicológica de esta observación es tan atinada como de sentido común. Cabe aquí plantear de qué manera la sociedad moderna, por su igualitarismo, multiplica las ocasiones de experimentar la envidia. Numerosas aproximaciones sociológicas contemporáneas (Tocqueville, Merton, Lipovetsky, etc.) al fenómeno de la igualdad y sus desviaciones están emparentadas con estas observaciones tomasianas.

También en Scheler resulta la envidia resentida no meramente del deseo de un objeto poseído por otro sino de la ilusión o autoengaño consistente en ver al otro como la causa de que uno mismo no posea el objeto en cuestión: 
La "envidia", en el sentido usual de la palabra, surge del sentimiento de impotencia que se opone a la aspiración hacia un bien, por el hecho de que otro lo posee. Pero el conflicto entre esta aspiración y esta impotencia no conduce a la envidia, sino cuando se descarga en un acto o en una actitud de odio contra el poseedor de aquel bien; cuando, por virtud de una ilusión, nos parece que el otro y su posesión son la causa de que nosotros no poseamos (dolorosamente) el bien (Scheler 1998, 28)

La mera aspiración a un bien y el fracaso de no alcanzarlo no da lugar a la envidia. Hace falta que ese bien sea alcanzado por otro que no sea muy diferente ni muy alejado de mí. Es entonces cuando surge la envidia. Y esa envidia es puro resentimiento cuando encuentra insoportable la existencia misma del otro e incluso la propia identidad personal: "Esta envidia murmura, por decirlo así, continuamente: 'Puedo perdonártelo todo, menos que seas y que seas el que eres; menos que yo no sea lo que tú eres, que 'yo' no sea 'tú". Esta 'envidia' ataca a la persona extraña en su pura existencia que como tal es sentida cual 'opresión', 'reproche' y temible medida de la propia persona.” (Scheler 1998, 28)

\subsection{Conflictos generacionales}

La distancia intergeneracional y sus conflictos son objeto de atención tanto de santo Tomás de Aquino como de Max Scheler cuando tratan la envidia y el resentimiento. El Aquinate se apoya en la Retórica de Aristóteles para referirse a un tipo de envidia que surge frecuentemente en los viejos respecto a los jóvenes. Tal envidia es resultado de la constatación, por parte de los viejos, de la imposibilidad de tomar parte en bienes que están fácilmente al alcance de los jóvenes. Si los viejos lograran simplemente recordar los bienes de que disfrutaron en su juventud, experimentarían cierta alegría. Sin embargo, cuando ponen la atención en aquellos que los experimentan ahora, pueden caer en la envidia porque comparan lo que en ellos, los viejos, es solo un recuerdo, con lo que en los jóvenes es una realidad bien presente. En su caso extremo, esta tristeza se convierte en una deformación atormentada del propio recuerdo de las experiencias vividas: 
el recuerdo de los bienes pasados, en cuanto fueron poseídos, causan alegría; pero en cuanto se han perdido, tristeza; envidia en cuanto los tienen los otros, porque eso parece que cercena la propia gloria. Así dice el Filósofo en II Rhet. que los viejos envidian a los jóvenes, y los que perdieron mucho por conseguir algo, a los que lo consiguieron con pocos gastos pues se duelen de la pérdida de sus bienes y de que otros los hayan conseguido. (Tomás de Aquino 1995, 324)

Por su parte, Scheler hace hincapié en cómo una envidia intergeneracional de este tipo será mayor aún en aquellas culturas en que los valores tradicionalmente asociados a la edad adulta y a la experiencia queden rebajados y superados por los valores propios de la juventud. En la medida en que el mundo contemporáneo ha experimentado cierta primacía del espíritu juvenil frente a la secular veneración hacia los mayores, resulta comprensible la extensión del resentimiento entre aquellas capas generacionales que han quedado fuera del protagonismo político y social. La idea misma de progreso se cierne sobre cualquier vestigio del eterno ayer generando así el resentimiento de los que no se han subido al tren de la historia (Scheler 1989, 39). De todas maneras, para Scheler este fenómeno tiene carácter universal, en mayor o menor medida, y es casi tan inevitable como el mismo envejecimiento biológico, aun teniendo en cuenta las múltiples variaciones históricas. Cuanto más rápidamente avanzan las comunicaciones, cuanto más rápidamente cambian los regímenes políticos, cuanto más se impone el espíritu de la inmediatez e incluso de la construcción ultrarrápida de edificios y autopistas, más expuestas están las generaciones de los mayores al resentimiento. Igual que para santo Tomás, siguiendo a Aristóteles, la envidia surge al constatar lo poco que les ha costado a otros lo que a nosotros nos costó tanto tiempo y tanto sacrificio, así para Scheler el resentimiento lleva a la generación mayor a despreciar incluso lo que de bueno pueda haber en el espíritu juvenil.

\subsection{El vicio de la crítica resentida}

Como es propio del resentimiento la incapacidad continuada para la acción, a menudo el resentido encuentra en la crítica verbal un sucedáneo con el que dar salida a la expresión de su odio profundo. Del mismo modo que en la fenomenología scheleriana del resentimiento podemos constatar cómo 
unos determinados sentimientos negativos pueden generar una serie de actitudes vitales y modos de comportarse degenerados, así también en el pensamiento medieval se señalaba la filiación de diversos vicios respecto a los vicios capitales, llamados así por ser como 'cabeza' de otros vicios.

En Gregorio Magno, a quien sigue en esto el Aquinate, son hijas de la envidia la murmuración, la detracción, la alegría ante la adversidad del prójimo y la aflicción por su prosperidad, mientras que Scheler considera consustancial al resentimiento la inacción combinada con el desprecio hacia ciertos bienes esquivos, como ocurre en el chismorreo, en la gazmoñería o, incluso, en la calumnia casquivana contra el pudor auténtico.

Santo Tomás sintetiza los pasos que da el que queda dominado por la envidia, estableciendo una secuencia lógico-moral: "Al principio, en efecto, hay un esfuerzo por disminuir la gloria ajena, bien sea ocultamente, y esto da lugar a la murmuración, bien sea a las claras, y esto produce la difamación" (Tomás de Aquino 1995, 327). Este fenómeno lo considera Scheler aplicable de modo notable en la mujer. Por su papel social pasivo y sin posibilidad de ejercer violencia alguna, la mujer se encuentra en peligro de resentimiento. De ahí "la fuerte inclinación de las mujeres al chisme detractor" (Scheler 1989, 37). Tras la murmuración y la difamación, puede darse como resultado bien una disminución de la fama del prójimo o bien no afectarle, cosa que produce en el envidioso respectivamente "la alegría en la adversidad, o [...] la aflicción en la prosperidad.” (Tomás de Aquino 1995, 327) Scheler señala algunos tipos de resentimiento que se dan repetidamente en situaciones parecidas y que fácilmente podemos comparar con las hijas de la envidia señaladas. Así, por ejemplo, el caso de la "solterona, cuyos impulsos sexuales de reproducción y de ternura han sido reprimidos, está raras veces libre del veneno del resentimiento." (Scheler 1998, 37-38) La solterona se alegra secretamente del fracaso en el matrimonio de una pareja joven o se intenta autoconvencer de que la mejor forma de vida es la soltería. De igual modo, la solterona resentida no soporta la prosperidad y felicidad visibles de matrimonios de su misma generación. Algo parecido ocurre con la gazmoñería, no exclusiva del género femenino, y que se opone al genuino pudor. Consiste aquella en "la continua inquisición de sucesos con sentido 
sexual, para hacer recaer sobre ellos duros juicios negativos de valor; esa caza de lo pecaminoso [...] no es sino una última forma de satisfacción sexual, que se ha transmutado en satisfacción del resentimiento. La crítica realiza aquí aquello mismo que en apariencia rechaza." (Scheler 1989, 38)

En un extremo aparentemente contrario a la gazmoñería, pero en el fondo fruto también del resentimiento, señala Scheler el caso de la calumnia casquivana, es decir, de la burla contra el verdadero pudor. En tal burla se confunde el mero convencionalismo social con la auténtica moral. Se trata de una incapacidad no reconocida para vivir de modo moralmente ordenado. Tal incapacidad se vuelve contra los mismos valores morales hasta el punto de despreciarlos y considerarlos como negativos y contrarios al progreso: "el tipo de la casquivana calumnia el pudor genuino de la verdadera mujer, el cual no sólo es bello en su expresión, sino que encubre justamente lo bello y lo conocido en la intimidad como dotado de un valor positivo; y lo calumnia atribuyéndolo a simple 'temor' de descubrir defectos corporales o de atavío." (Scheler 1989, 38) No está nada lejos esta caracterización scheleriana de aquella hija de la acedia que, siguiendo de nuevo a Gregorio Magno, denomina santo Tomás vagatio mentis circa illicita o divagación de la mente por lo ilícito, que se produce cuando "la tristeza debida a las cosas espirituales impulsa a pasar hacia los placeres exteriores" (Tomás de Aquino 1995, 322) y que también se manifiesta en la curiosidad, la verbosidad, la inquietud corporal y la inestabilidad. La acedia tal como la entiende santo Tomás de Aquino no se manifiesta únicamente en pereza o en inactividad, sino que se manifiesta aún más en forma de exceso desordenado de actividad. Ahora bien, ese exceso de actividad tiene su raíz en la falta de amor hacia los bienes verdaderamente superiores. De ahí que la curiosidad entendida como un constante ir y venir de la imaginación por diversos objetos o la inquietud corporal entendida como una incapacidad física para quedarse en un determinado lugar fueran especialmente peligrosos desde la óptica de la vida contemplativa, pero deban ser tenidos en cuenta en toda reflexión moral integral (DeYoung 2014, 196). Aunque es cierto que el resentimiento incluye un elemento de perversión del juicio intelectual que va más allá de la acedia: "El resentimiento nos lleva a una solución más sofisticada a la 
proporcionada por la venganza, la envidia o la acedia. Lo propio de él es que, llevado por su "engaño valorativo”, crea valores nuevos, trastocando los que existían previamente" (Droste 2005, 5), también es cierto que, en el análisis de santo Tomás de las hijas de la acedia, se dan elementos coincidentes y claramente precursores de la fenomenología scheleriana del resentimiento, tal como hemos visto en este artículo.

\section{Conclusión}

Estas dos formas viciosas de tristeza contrarias a la caridad, la acedia y la envidia, tanto se pueden traducir en una incapacidad radical para la acción (de ahí que a menudo se la confunda con la mera pereza) como en un activismo imparable que, en el fondo, esconde una profunda insatisfacción que busca compensarse con una multitud de estímulos agradables ante los cuales el acídico experimenta la frustración de no ser capaz de gozarlos. $\mathrm{Y}$, tanto en un caso como en otro, su eco se percibe en los diversos tipos de resentidos, y muy marcadamente en el alma romántica a la que, como hemos visto, Scheler considera un tipo especialmente proclive al resentimiento. Tanto el retrato tomista del hombre acídico como el hombre scheleriano del resentimiento, tan alejados en el tiempo y tan cercanos en su esencia, fueron captados brillantemente por un genio del barroco, Blaise Pascal, en su caracterización del hombre moderno incapaz de estar a solas consigo mismo, necesitado de una sucesión constante de juegos y entretenimientos para evitar a toda costa la manifestación del sentimiento de la propia nada: "Privadles de sus distracciones y les veréis languidecer de tedio. Se dan cuenta entonces de su vaciedad sin conocerla; porque es ser muy desgraciado sufrir una tristeza insoportable tan pronto como nos vemos reducidos a mirarnos a nosotros mismos y a no divertirnos de ello." (Pascal 1981, 360)

El análisis tomasiano de la acedia nos la muestra como una tristeza ante el bien espiritual, especialmente el bien divino; tristeza que apesadumbra, viciosa doblemente -en sí misma y en sus efectos- en sí misma porque nos entristecemos ante lo que es realmente bueno; en sus efectos porque adultera nuestra acción, bien sea por la indolencia en actuar bien sea por una especie 
de hiperactividad, pero siempre incapaces de perseverar en una misma operación. Vemos así que en el acídico hay una cierta incapacidad para el bien superior. Algo semejante le ocurre al resentido scheleriano. Pero en lugar de intentar sobreponerse a esta incapacidad, se da una huida - una 'huida de la celda' diría Evagrio Póntico- hacia bienes inferiores. En tal huida no sólo se buscan placeres que compensen la incapacidad para el gozo previamente experimentada, sino que se impugnan los bienes superiores e incluso se impugna a las personas que nos los proponen, lo cual constituye el rencor propiamente dicho. Una huida semejante es la que Scheler denuncia en los entresijos de numerosos movimientos sociales y políticos contemporáneos.

Creemos que el fenómeno del resentimiento tal como lo plantea Nietzsche y sobre todo, más tarde, Scheler, es mucho más inteligible si se lo compara con el análisis tomista de la acedia y la envidia. También el resentido experimenta una impotencia continuada respecto a un bien superior inalcanzado. En lugar de reconocer su incapacidad e intentar sobreponerse, el resentido niega la realidad hasta el punto de invertir los valores morales mismos. El resentido tampoco se ve a sí mismo como tal sino como indignado que reclama deudas pendientes.

Si bien Nietzsche no tuvo especial interés en proveernos de instrumentos de prevención y lucha contra el resentimiento y sus frutos, sino que directamente todo su proyecto vital viene a ser un proyecto contra lo que él consideraba la más fina flor del resentimiento -el cristianismo-, Max Scheler sí que procura advertirnos del peligro real de contagio del resentimiento no sólo en las filas de la filantropía moderna sino incluso en ciertos sucedáneos del Evangelio. Hemos podido comprobar de qué manera el Aquinate se adelantó siglos antes ofreciendo unas reflexiones sobre la acedia y la envidia que resultan de perenne actualidad.

\section{Bibliografía}

Butler, Joseph. 1896. The Works of Joseph Butler. Volume 2. Oxford: Clarendon Press. DeYoung, Rebeca Konyndyk. 2014. "Sloth: Some Historical Reflections on Laziness, Effort, and Resistance to the Demands of Love." In Virtues and Their Vices, edited by Kevin Timpe, and Craig A. Boyd, 177-198. Oxford: Oxford University Press. 
Droste, Klaus. 2005. “Resentimiento y Psiquismo.” Summa Psicológica. 1 (2) 3-6.

Echavarría, Martín. 2016. “El corazón: un análisis de la afectividad sensitiva y la afectividad intelectual en la psicología de Tomás de Aquino.” Espíritu. 65 (151) 41-72.

Giertych, Wojciech. 2019. “Acedia as Spiritual Sadness.” In Le emozioni secondo san Tommaso, a cura di S.Th. Bonino e G. Mazzota, 201-218. Roma: Urbaniana University Press.

Girard, René. 1985. Mentira romántica y verdad novelesca. Barcelona: Anagrama.

Gudaniec, Arkadiusz. 2016. “Amore e belleza - contemplazione e compiacenza: riflessioni sulla base del pensiero di san Tommaso d’Aquino” Espíritu. 65 (151) 85-99.

La Caze, Marguerite. 2001. “Envy and Resentment.” Philosophical Explorations 4 (1) $31-45$.

Martínez, Enrique. 2019. “Las pasiones en la educación.” In Le emozioni secondo san Tommaso, a cura di S.Th. Bonino e G. Mazzota, 239-258. Roma: Urbaniana University Press.

Nietzsche, Friedrich. 1971. La genealogía de la moral. Madrid: Alianza.

Pascal, Blaise. 1981. Obras. Madrid: Alfaguara.

Peretó Rivas, Rubén. 2011. "Las mutaciones de la acedia. De la Patrística a la Edad Media.” Studium. Filosofía y Teología 27:157-171.

Perrine, Timothy, and Kevin Timpe. 2014. "Envy and Its Discontents.” In Virtues and Their Vices, edited by Kevin Timpe, and Craig A. Boyd, 225-244. Oxford: Oxford University Press.

Pieper, Josef. 1980. Las virtudes fundamentales. Madrid: Rialp.

Roszak, Piotr, and Jörgen Vijgen. 2015. Reading Sacred Scripture with Thomas Aquinas. Hermeneutical Tools, Theological Questions and New Perspectives. Turnhout: Brepols.

Quesada, José Jorge. 2010. “Un maestro ruso renuente a las escuelas del resentimiento.” Estudios 94 (3) 221-230.

Scheler, Max. 1998. El resentimiento en la moral. Madrid: Caparrós Editores.

Stendhal. 2014. Rojo y negro. Crónica del siglo XIX. Crónica de 1830. Barcelona: Alba. Teresa de Jesús. 1984. La vida. Las moradas. Barcelona: Planeta.

Tomás de Aquino. 1995. Suma de Teología. Madrid: BAC. 